\title{
INTRODUCTION TO THE TWO FICE SPECIAL ISSUES
}

\section{Emmanuel Grupper, James P. Anglin, and Silke B. Gahleitner Guest editors}

This is the first of two special issues based on materials presented at the FICE International Congress in Vienna, Austria in August 2016. The theme of the congress was "Together Towards a Better World for Children, Adolescents, and Families". The same theme was chosen for these special issues. Child and youth care professionals who presented their quality material in the congress were invited to rework their presentations as formal papers meeting the norms of a scientific journal. FICE International is most thankful to the guest editors, Jim Anglin, Silke Gahleitner, and Emmanuel Grupper, who worked with all the contributors to prepare their materials for publication. We also want to thank Dr. Sibylle Artz, the editor of IJCYFS, for giving us the opportunity to publish this material in an open-access electronic journal and in that way share it with a much broader audience.

Emmanuel Grupper PhD is Vice-President FICE-International, and Associate Professor at the School of Education and Social Studies at the Ono Academic College, 104 Zahal St., Kiryat Ono 5545173, Israel. Email: emmanuel.g@ ono.ac.il

James P. Anglin PhD is Full Professor at the School of Child and Youth Care, University of Victoria, PO Box 1700 STN CSC, Victoria, BC V8W 2Y2, Canada. Email: janglin@uvic.ca

Silke Birgitta Gahleitner $\mathrm{PhD}$ is a Professor at the Alice Salomon University of Applied Sciences Berlin - Arbeitsbereich Psychosoziale Diagnostik und Intervention, Alice-SalomonPlatz 5, D-12627 Berlin, Germany. Email: sb@gahleitner.net 
International Journal of Child, Youth and Family Studies (2018) 9(1): 1-4

Child and youth care professionals are often confronted with the dilemma of having to choose between a utopian vision of a better world for all people and a more concrete vision of a better world for vulnerable populations of children, youth, and their families who are in need of specialized services.

Although we would like to believe in a utopian world where all children could grow up leading secure lives with their biological families, we have to face the reality that large numbers of children and young people are confronted with hardship, danger, and neglect. Such conditions create masses of socially excluded children and young people who need specialized services for a variety of reasons. Let us take as an example the large numbers of refugee youth who have become a significant proportion of excluded youth in many industrialised and developed countries. Many of these young people have left their homes and families behind because of wars, famine, lack of resources, and absence of future prospects; they have headed to other countries where they hope to find better life conditions and opportunities. In 2013, the International Migration Organization (IMO) published an important report entitled "Children on the Move" to document this large-scale movement of children and young people, often without their families, which is a reality in many countries, and challenges child and youth care workers everywhere and at all levels.

Whenever we child and youth care professionals think of a better world for children, adolescents, and families, therefore, we have in mind better services and better opportunities for education, empowerment, and support for children and young people from vulnerable families and communities.

While there are still many challenges ahead of us, we can be proud of recent developments that represent a major improvement in services for these young people that offer them a better future. As an example, let us look at the transition from care to independent life. Since the beginning of the third millennium, it has become generally accepted that services for children and youth who are in need of care should include a "safety net" and quality programs for supporting care leavers. It is encouraging to see among many of the papers presented in this special issue that this relatively new concept is already being applied around the world and not only in well-established and relatively rich countries.

The two special issues emerging from the 2016 FICE International Congress are divided into three clusters of articles. The first cluster consists of four papers focused on Trauma and Neuroscience. The second cluster, with six papers on the theme of National Perspectives Leading to an International One, also appears in this first of the two issues. The third cluster, comprising eight papers dealing with Evaluation, Research, and Challenges in Residential, Foster, and Family Care, occupies the whole of the second issue. 
International Journal of Child, Youth and Family Studies (2018) 9(1): 1-4

\section{Cluster 1: Trauma and Neuroscience}

Isabella Sarto-Jackson, from Austria, authors the first paper in this cluster. She is looking at the roots of psychological trauma, and presents an original interdisciplinary approach that combines neurobiology, evolutionary biology, and social pedagogy. Another group of Austrian professionals — Silke Gahleitner, Christina Frank, Katharina Gerlich, Heidemarie Hinterwallner, Martha Schneider, and Hermann Radler — present the results of a research project on trauma pedagogy in residential care facilities for children and youth in Austria. They summarize their insights in a phrase from one of the children in their study: "Otherwise I might not have been able to cope at all." Readers who are curious to understand the meaning of this remark are invited to read the full article. Susan Hunt, Marlene Moretti, Chris Booth, and Nickole Reyda are Canadian professionals from British Columbia. They share with us the results of their evidencebased research looking at the possibility of promoting change among clients by using traumainformed perspectives. This could been seen as an example of applying theoretical principles to practice.

\section{Cluster 2: National Perspectives Leading to an International One}

The second cluster opens with a paper by Nilika Dutta investigating street children in India and the health education issues they experience. In their contribution, from Serbia, Anita Burgund Isakov and Jasna Hrnčić deal with leaving alternative care from the perspective of Serbian researchers, and offer several recommendations for improving outcomes for care leavers. Stephan Sting from Austria reminds us of new developments in classical social pedagogy practices for working with children and young people in his country, while three Japanese scholars, Shigeyuki Mori, Satoru Nishizawa, and Arimi Kimura, present in their paper actual developments in out-of-home care in Japan, and the challenges of trying to enhance foster care services that have been almost nonexistent in the past. Next, Anna Schmid from Switzerland and her Hungarian colleague Krisztián Herczeg focus their paper on the great potential for improvement in residential care services by close collaboration between professionals from different countries. The concluding paper is by Varda Mann-Feder of Concordia University in Montreal, Canada, who looks at a prominent issue in the child and youth care field: care leavers. Her insights from a field study show interesting relationships between three variables: care leaving, friendships, and agency policy.

\section{Cluster 3: Evaluation, Research, and Challenges in Residential, Foster, and Family Care}

The first paper in this third cluster is by Zsolt Major of Hungary. His qualitative research done in residential care homes in Hungary examines relationships between professional selfesteem and organizational developments. A paper from German researchers Michael Macsenaere and Corinna Pummer-Pilaj looks at success and failure in residential care, and offers insights based on a large-scale evaluation of child and youth care. Next, three Swiss researchers, Clara Bombach, Thomas Gabriel, and Renate Stohler, focus on the complexities of foster care and the factors that can bring about breakdown. From Austria, Andrea Nagy looks in her paper at the 
experiences of care leavers. Her insights are based on a consideration of residential care alumni and the possibility of their becoming autonomous in a residential care facility. Ivan Lukšik and Lucia Hargašová from Slovakia also focus on care leavers. Their particular interest relates to the potential relationships between residential care cultures and the quality of life of young adult care leavers. Kira Amman from Switzerland contributes a perspective on moral developmental thinking of children between 8 and 12 years old, and how they learn to distinguish right from wrong. Next, South African professional Rika Swanzen casts a light on the generation chasm as it exists today, with detailed consideration of generations $\mathrm{Y}$ and $\mathrm{Z}$, and the implications of generational characteristics for pedagogy. The final paper, by Satarupa Dutta, deals with the preparation of young girls in India for their integration into society after they leave residential care facilities.

\section{Closing Remarks}

In summary, the papers presented in this special issue are written by professionals practising in 12 different countries, writing from locations as disparate as North America, Europe, the Middle East, India, and Japan. The topics are varied, but taken together we can see in them the reflection of meaningful improvements in the quality of services for children, adolescents, and families in at-risk situations. These important ongoing developments can give us hope that we are on the way, albeit with small steps, towards a better world for children, youth, and families - the theme of these special issues.

\section{In Memoriam Carol Kelly}

In February 2017, when we were in the midst of our work on this special issue we were deeply saddened by the news of the passing of Dr. Carol Kelly from California who served for many years as representative of FICE USA in FICE International. We are pleased to add a short Memoriam by Bettina Terp and Varda Mann-Feder as a tribute to Carol's great contributions towards making a better world for children, youth, and their families. 